\title{
Trayectorias sociales de jóvenes comerciantes ambulantes en la ciudad de El Alto
}

Parcours sociaux de jeunes commerçants ambulants de la ville d'El Alto

Social trajectory of young street vendors in the city of El Alto

\section{Héctor Luna Acevedo}

\section{(2) OpenEdition}

Journals

Edición electrónica

URL: http://journals.openedition.org/bifea/7700

DOI: $10.4000 /$ bifea. 7700

ISSN: 2076-5827

Editor

Institut Français d'Études Andines

Edición impresa

Fecha de publicación: 1 diciembre 2015

Paginación: 447-462

ISSN: 0303-7495

Referencia electrónica

Héctor Luna Acevedo, «Trayectorias sociales de jóvenes comerciantes ambulantes en la ciudad de El Alto », Bulletin de l'Institut français d'études andines [En línea], 44 (3) | 2015, Publicado el 08 diciembre 2015, consultado el 05 noviembre 2020. URL : http://journals.openedition.org/bifea/7700 ; DOI : https://doi.org/10.4000/bifea.7700

\section{(c) $98 \%$}

Les contenus du Bulletin de l'Institut français d'études andines sont mis à disposition selon les termes de la licence Creative Commons Attribution - Pas d'Utilisation Commerciale - Pas de Modification 4.0 International. 


\title{
Trayectorias sociales de jóvenes comerciantes ambulantes en la ciudad de El Alto
}

\author{
Héctor Luna Acevedo*
}

\begin{abstract}
Resumen
El comercio informal representa una fuente de ingresos importantes para los jóvenes comerciantes ambulantes de la ciudad de El Alto. Entre 15 y 30 años, representan el 30\% del total de la población del municipio, donde una proporción significativa de ellos, a parte de tener alguna actividad comercial, estudian en colegios de secundaria o en un centro de formación superior. Esta realidad expresa una combinación entre la actividad comercial y estudiantil. Ambas son imprescindibles para garantizar un futuro laboral y social que permite alcanzar un estatus en el contexto urbano. Asimismo, las necesidades del entorno familiar impulsan a los jóvenes para incursionar en actividades comerciales. A esto se suman factores como la necesidad de ingresos inmediatos, la flexibilidad de los horarios, la independencia laboral, la capacidad de decidir por sí mismos y la facilidad de administrar el tiempo entre la formación y el comercio ambulante.
\end{abstract}

Palabras clave: trayectoria social, comercio ambulante, jóvenes, precariedad, El Alto

\section{Parcours sociaux de jeunes commerçants ambulants de la ville d'El Alto}

\section{Résumé}

Le commerce informel représente une source de revenus importante pour les jeunes commerçants ambulants de la ville d'El Alto. Ceux âgés entre 15 et 30 ans représentent, d'après le recensement de 2012, 30\% du total de la population de la municipalité où une proportion significative de jeunes, en plus de travailler, étudient au collège ou dans un centre de formation supérieure. Cette réalité

Sociólogo, investigador en temas de derechos indígenas, pluralismo social, político, jurídico, descolonización, de la Secretaría Técnica y Descolonización del Tribunal Constitucional Plurinacional, Sucre-Bolivia. E-mail: lunaayrampu@ gmail.com 
exprime une combinaison entre l'activité commerciale et estudiantine. Les deux sont indispensables pour assurer un avenir professionnel et social permettant d'obtenir un statut dans le contexte urbain. De même, les besoins de l'entourage familial influencent les jeunes à participer aux activités commerciales. À cela s'ajoutent des facteurs tels que le besoin de revenus immédiats, la flexibilité des horaires, l'indépendance sur le lieu de travail, la capacité à décider soi-même de ses activités et la facilité à gérer le temps entre la formation et le commerce ambulant.

Mots-clés : parcours social, commerce ambulant, jeunes, précarité, El Alto

\title{
Social trajectory of young street vendors in the city of El Alto
}

\begin{abstract}
Informal trade is an important source of income for young street vendors in the city of El Alto. Those between 15 and 30 represents, according to the 2012 census $30 \%$ of the total population of the municipality where a significant proportion of young people in addition to working study in secondary school or higher education center. This reality expresses a combination between business and studying. Both are essential to ensure a professional and social future to obtain a status in the urban context. Similarly, the needs of family environment influence youth to participate in commercial activities. Added to this are factors such as the need immediate income, schedule flexible, job independence, the ability to decide for one selves its activities and the facility to manage time between training and street trading.
\end{abstract}

Keywords: social history, street vendors, youth, El Alto

\section{INTRODUCCIÓN}

El comercio ambulante representa una fuente laboral para los jóvenes de la ciudad de El Alto en Bolivia, que se ha convertido en un campo de estudio para las ciencias sociales desde la década de 1980 (Sandoval \& Sostres, 1989; Fernández, 2001; Pereira et al., 2009; Tassi et al., 2013; Q uispe et al., 2011). Este fenómeno surge por las características culturales, económicas, políticas, demográficas y territoriales que ha expresado el proceso de urbanización de esta joven ciudad. Según los datos del Instituto Nacional de Estadística (INE), la ciudad de El Alto cuenta con 848452 habitantes, de los cuales 408984 son varones y 439468 son mujeres. La población joven comprendida entre 15 y 29 años representa el $30 \%$ del total de la población del municipio1. El crecimiento demográfico lo convierte en la segunda ciudad más poblada del país (INE, 2014). Un aspecto transversal a la constitución urbana fue la migración campo-ciudad, que no ha cesado desde la década de los años 1980, desembocando en elevados índices de

1 Las investigaciones que se refieren al comercio informal se basan en exploraciones sobre la situación de vendedores en ciudades como Lima, M éxico D.F., Bogotá, Santiago, Buenos Aires y La Paz. 
pobreza que afecta al $66,9 \%$ de la población (INE, 2014), siendo superior a las ciudades de La Paz, Cochabamba y Santa Cruz. Esta situación se manifiesta en las demandas de fuentes de trabajo, vivienda, educación, salud, dotación de servicios básicos y seguridad ciudadana. Estos factores articulan las movilizaciones de la población alteña, encabezada por organizaciones matrices como la Federación de Juntas Vecinales, Gremiales, como la Central Obrera Regional (COR)2 y la Federación de Gremiales, las cuales demandan al municipio la ejecución de proyectos que resuelvan las necesidades de los sectores sociales.

En el aspecto económico, la U nidad de Análisis de Políticas Económicas y Sociales (UDAPE) menciona que el crecimiento de la economía nacional fue en asenso desde el año 2000 alcanzando un promedio de 2,51\%. Luego este dato se ha incrementado para llegar a un 6,15\% en el año 2008; después se ha dado una caída hasta el 3,36\% en 2009 (Canavire-Bacarreza \& Mariscal, 2010), aunque posteriormente, según el Instituto Nacional de Estadística (INE) se ha observado un ascenso entre 2010 y 2014 con un 5,37\%, siendo el año 2013 el más alto con un $6,78 \%$. Sin embargo, cabe plantear como hipótesis, que el crecimiento de la economía en la primera década del siglo XXI en relación a la ciudad de El Alto ha incentivado la expansión del comercio informal y sobre todo del comercio minorista en las ferias de los días jueves, sábado y domingo, a donde acuden los clientes no solo de las ciudades de El Alto y La Paz, sino también de otros departamentos del país, que vienen de compras a la feria 16 de Julio, por los bajos costos y la variedad de productos que se ofertan.

La situación socioeconómica de la población alteña refleja los problemas sobre las escazas oportunidades de acceso a un empleo formal, que en la actualidad es inferior a la cantidad de empleos por cuenta propia, donde las familias por la premura de obtener ingresos se ven ante la necesidad de generar sus propias fuentes de trabajo. Por otro lado, la proporción de la mano de obra calificada es menor a la de la mano de obra no calificada; es decir, la mayoría de la población ocupada en algún tipo de empleo no está calificada con un título académico (Escobar \& Guaygua, 2008). Por ello, las actividades laborales por cuenta propia representan el único medio que les permite generar ingresos de forma autónoma. En esta tarea, los jefes de hogar se encargan de llevar el sustento económico a sus familias. Eso significa que los problemas de acceso a un trabajo formal tienen como efecto la creación de estrategias de empleo por cuenta propia, en las cuales, no hay diferencia entre el empleador y los empleados. Con frecuencia, estas actividades autogeneradas ocupan al conjunto de una familia nuclear en un oficio, para producir y comercializar bienes o servicios. En esa situación, se observan a niños, jóvenes, adultos, adultos mayores entre varones y mujeres que provienen del área rural, como también, de las ciudades de El Alto, La Paz y del interior del país.

2 La Provincia Bolívar y el Norte de Potosí son parte de un mismo piso ecológico y cultural, aunque la provincia Bolívar pertenece a Cochabamba y el Norte de Potosí a la Provincia Bustillos del departamento de Potosí. 
Por tanto, dentro de las actividades del comercio informal está incluida la venta por unidad de productos que ofertan los ambulantes. Este tipo de comercio al detalle se incrementa en forma cuantitativa desde 2006, y se expande por calles, avenidas y plazas de los distritos uno y seis de la ciudad de El Alto3, sobre todo, el casco urbano de la Ceja y la zona 16 de Julio. El comercio ambulante es una fuente de trabajo para cientos de jóvenes que recorren diferentes calles, ferias y plazas llevando mercadería en carros móviles. Según datos del censo nacional de población y vivienda 2012 (INE, 2014), en la ciudad de El Alto existen 104148 habitantes que tienen como actividad económica el comercio al por mayor y menor. Entre ellos, 8323 habitantes (8\%) entre 15 y 19 años de edad se dedican al comercio al por mayor y menor, mientras que 13019 habitantes (13\%) entre 20 y 24 años de edad se dedican a la misma actividad comercial. De igual forma, los datos del Censo 2012 indican que en la ciudad de El Alto existen 25473 jóvenes entre 15 y 24 años de edad que son trabajadores en servicios y vendedores.

El concepto de trayectoria social es una categoría teórica de la sociología contemporánea, que explica el comportamiento social de la vida de una persona o grupo social; existen varios subcomponentes teóricos, como trayectoria laboral, familiar, escolar, política (Cachón, 2001; Bourdieu, 1998). En ese sentido, la trayectoria social de los comerciantes ambulantes es el recorrido laboral, familiar, de relaciones sociales desde las actividades primarias que comienza desde la niñez, para algunos, en las comunidades rurales, para otros, en un contexto familiar urbano. Posteriormente incursionan en empleos precarios en el área urbana, lo que motiva la inserción en la actividad comercial ambulante.

Por tanto, en los contenidos siguientes del artículo se pretende responder a las siguientes preguntas, ¿cuáles son los factores que promueven la inserción al comercio ambulante? y ¿cuál es la orientación de la trayectoria social de los jóvenes comerciantes ambulantes en relación a su procedencia social y geográfica?

\section{EL COMERCIO AMBULANTE DESDE LAS INVESTIGACIONES SOCIALES Y ECO NÓ MICAS}

En el presente acápite describimos algunas investigaciones que se refieren al comercio ambulante como una actividad del comercio informal y del sector informal urbano. Siendo una característica en ciudades donde el sector informal supera el $60 \%$ en comparación con la población ocupada en un empleo regulado por el Estado. El crecimiento de la economía informal se interpreta en América Latina desde dos posiciones: primero, la perspectiva liberal concibe como aquellas actividades económicas creadas por sectores de bajos ingresos económicos, principalmente por la población migrante del área rural que vive por debajo de

3 Para los jóvenes que provienen del área rural, no hay diferencia entre contactos por amistad y paisanaje, representa un sinónimo. Si se trata de jóvenes que provienen de una misma provincia 0 pueblo rural, se colaboran como amigos. 
Trayectorias sociales de jóvenes comerciantes ambulantes en la ciudad de El Alto

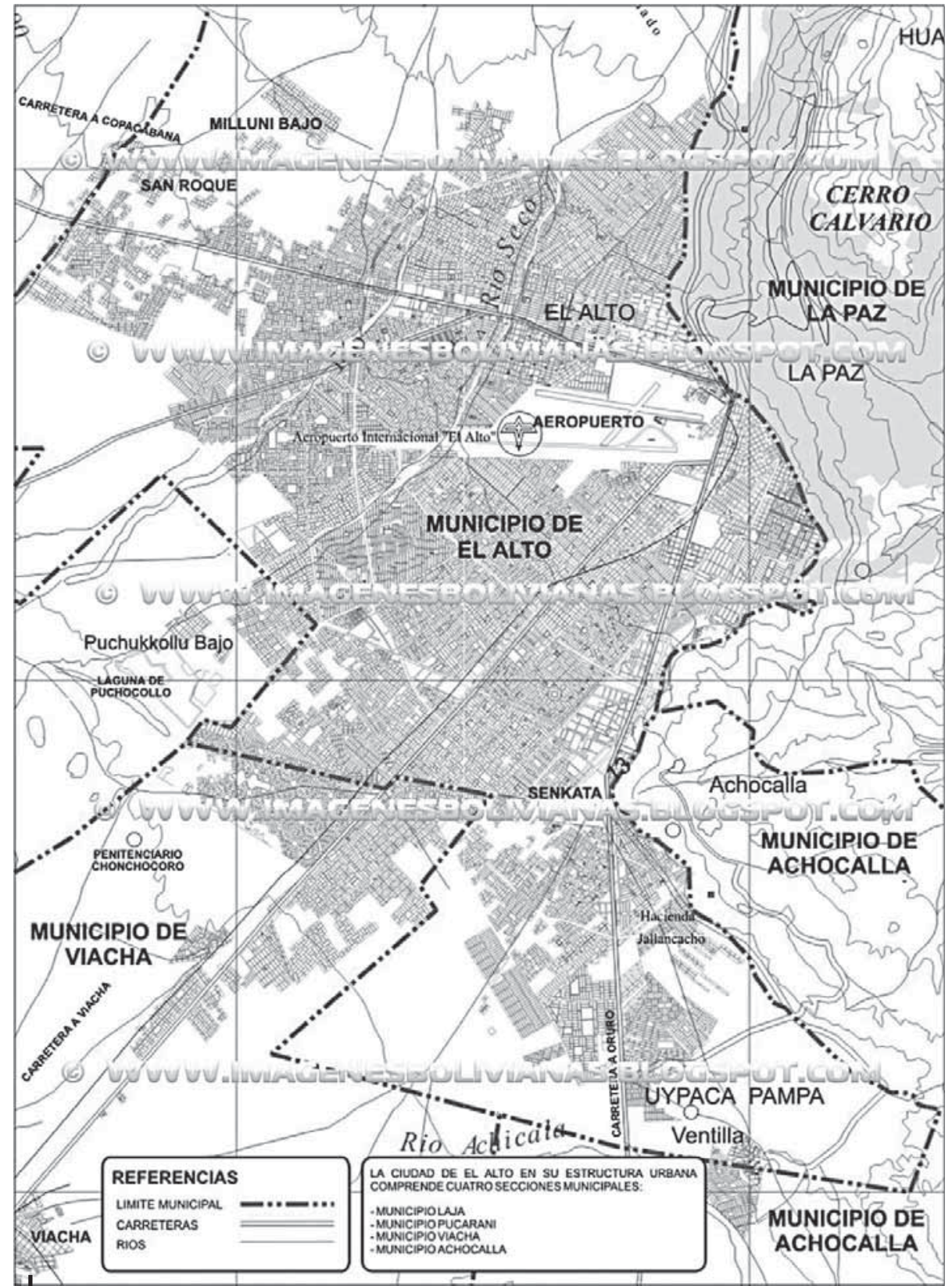

Figura 1 - Mapa de la ciudad de El Alto

Fuente:http://imagenesbolivianas.blogspot.com/2011/04/plano-de-la-ciudad-de-el-alto-bolivia. $\mathrm{html}$ 
los niveles de pobreza. El mismo enfoque afirma que estas iniciativas surgen por la dificultad que tiene el Estado en absorber a la población desocupada hacia empleos formales. En ese sentido, se explica la forma en que estas actividades se incrementan en diferentes ciudades de América Latina como Lima, Santiago, La Paz, Bogotá (Ardaya, 1988; Soto, 1986; Gálvez \& Jaramillo, 2002); es decir, se plantea una valoración positiva de los emprendimientos que realizan las poblaciones migrantes cuando autoestablecen sus propias fuentes de ingreso económico. La posición marxista constituye otro enfoque que proviene de los años 1970 y 1980; concibe el desempeño de estas actividades como resultado de una economía capitalista dependiente con respecto a los países desarrollados, que absorbe la riqueza y fuerza de trabajo de los países del tercer mundo, lo que deriva en el crecimiento de sectores pobres en países en vías de desarrollo.

Desde esas posiciones se fueron acuñando los conceptos de Sector Informal U rbano (S.I.U.) y comercio informal (C.I.) para diferenciar las formas de autoempleo de los sectores urbanos populares del ámbito de la economía formal o de aquellas actividades económicas reguladas por las leyes del Estado, como por ejemplo, ser trabajadores de empresas donde el salario se fija en función del mérito. En cambio, lo informal se caracteriza por la ausencia de cualquier forma de regulación estatal a toda actividad comercial transaccional. Es así como no existe una política tributaria sobre las actividades informales, siendo común en amplios sectores de ciudades metrópolis en América Latina4. So bre estos temas se encuentran varias investigaciones referidas a la actividad comercial ambulante que a continuación se describe.

En una investigación, Hernando De Soto estudia la situación de los migrantes de Lima y su incorporación en el mundo de la informalidad (Soto, 1986). Soto considera la migración como un desplazamiento de población del campo a la ciudad, y la informalidad se origina cuando el derecho excede las normas sociales aceptadas por la sociedad (Soto, 1986:12), es decir la norma no está en condiciones de ser factible en la realidad social porque esta es más compleja. Por tanto, el individuo por obligación rompe con estas normas y a consecuencia recibe un trato hostil, discriminatorio por parte de las élites citadinas. Según Soto, el ambulante itinerante es el vendedor que deambula con su mercadería por las calles, tratando de venderla entre las personas que encuentra a su paso (Soto, 1986: 15); y tienden a buscar al cliente en lugares céntricos. El ambulante de lugar fijo es el vendedor que lleva su producto en un carrito y se estaciona en un lugar fijo para vender su mercadería. El itinerante es una primera etapa para reconocer el espacio y vender mejor, luego se convierte en ambulante fijo.

En una investigación sobre las trabajadoras informales de La Paz, Gloria Ardaya aborda el comercio minorista y ambulante como una actividad realizada por mujeres que se dedican a la venta de una diversidad de productos en diferentes calles y avenidas de La Paz y El Alto (Ardaya, 1988). Según esta autora el comercio ambulante no requiere ningún requisito, lo que permite a muchas mujeres con

4 Las investigaciones que se refieren al comercio informal se basan en exploraciones sobre la situación de vendedores en ciudades como Lima, México D.F., Bogotá, Santiago, Buenos Aires y La Paz. 
baja formación escolar convertirse en comerciantes. Asimismo Ardaya describe el trato diferenciado que los gendarmes del municipio tienen para con las mujeres en situaciones de conflicto, pues no pueden expulsar a las comerciantes, porque muchas de ellas venden acompañadas por sus hijos. La gente del lugar, al observar las defiende para que las dejen vender, y no las expulsen de sus lugares de venta. Los gendarmes sacan a los comerciantes ambulantes varones de algún sitio público sin encontrar mayor resistencia por parte de ellos; mientras que con las mujeres vendedoras existe mayor consideración. Esto significa que las mujeres, al llevar a sus hijos pequeños, utilizan una estrategia de defensa ante los posibles atropellos de la gendarmería municipal. Sobre el acceso al comercio ambulante, Ardaya señala:

En el caso de la venta ambulante, este obstáculo no existe como barrera, ya que la mayor parte de las mujeres vendedoras ambulantes tienen un nivel mínimo de escolaridad y, en algunos casos, son analfabetas, lo que indudablemente repercutirá en el índice de ganancias y movilidad intrasector (Ardaya, 1988: 203).

Según Ardaya si hay tantas mujeres comerciantes ambulantes y de puestos fijos, es porque muchas son jefas de hogar, o son divorciadas que asumen responsabilidades de generar ingresos para sus hijos.

El Programa Regional de América Latina y Caribe (PREALC) de la Organización Internacional del Trabajo (O IT), estudia la situación de los vendedores ambulantes en Santiago de Chile, considerada una actividad ilícita por los carabineros y la intendencia municipal (PREALC, 1988). La investigación se basa en veinte entrevistas; en cada una de ellas los vendedores manifiestan las razones por las que se dedicaron al comercio ambulante, que en su mayoría fue por la pérdida de empleo; también por la influencia de un familiar que les obligaron a vender en las calles. La mayor proporción de vendedores (75\%) tienen entre 25 y 50 años y son jefes de familia que estuvieron en un empleo/trabajo anterior como albañil 0 vendedor en una tienda. La investigación aborda aspectos concernientes a la trayectoria social y laboral, cuando menciona dos tipos de inserción: voluntaria, por iniciativa propia, y coercitiva que trata de problemas que afectan a una familia, sobre todo cuando esta tiene bajos ingresos económicos, lo que obliga a los hijos a salir para vender.

O tra investigación vinculada con el comercio ambulante, de Arteaga y Larrazábal, estudia la realidad de las mujeres ambulantes, semiambulantes urbanas de La Paz (Artega \& Larrázabal, 1988). Las mujeres están obligadas a vender porque los ingresos que provee un padre de familia o esposo es demasiado limitado. Existe también la coerción de los padres o cónyuges para que los miembros de la familia se dediquen a vender. Las autoras mencionan la crisis económica como causa del aumento del comercio informal y de la salida de las mujeres a salir a vender en la calle. Describen tres tipos de vendedoras ambulantes: (1) comideras, (2) manufacturas, (3) carne. También abordan los conflictos con la alcaldía, especialmente de las libres cambistas y la subordinación del marido hacia las mujeres. Según las autoras, el comercio ambulante es una etapa para ser considerado dentro del comercio informal. 
En otra investigación, Rojas estudia las relaciones conflictivas al interior de los vendedores de puestos fijos, en las zonas comerciales de La Paz (Rojas, 1992). Los conflictos que se suceden son por el espacio público que es el lugar donde un comerciante realiza su vida cotidiana. También estudia la forma de la organización de los comerciantes:

[... ] las asociaciones poseen un funcionamiento autónomo. Este se traduce en la capacidad de control del espacio ocupado en la solución de los problemas emergentes (Rojas, 1992: 26).

Rojas clasifica tres tipos de comerciantes, vendedores ambulantes, vendedores de puestos fijos y el vendedor que tiene una tienda establecida. También clasifica los tipos de producto: abarrotes, verduras, prendas de vestir, mercachifles y ropa usada.

Finalmente desde un enfoque de género, Q uispe y otros abordan la investigación sobre las mujeres vendedoras de los mercados de la ciudad de El Alto (Q uispe et al., 2011). Los investigadores recogen testimonios de mujeres jóvenes adultas que se dedican al comercio de verduras, productos comestibles en puestos fijos y como ambulantes. Según los autores, los factores que impulsan a este tipo de actividades son la falta de empleo, los bajos niveles de formación escolar, los que inducen muchas mujeres a dedicarse a vender en ferias y en áreas comerciales de la ciudad de El Alto. Asimismo, existen otras investigaciones en referencia a la actividad comercial en vía pública desarrollada por jóvenes comerciantes ambulantes y de puestos fijos en la ciudad de La Paz (Pereira et al., 2009). Por otro lado, el artículo sobre los jóvenes lustra calzados de la ciudad de La Paz (Scarnecchia \& Cavagnoud, 20013), trata de los niños que se dedican a este oficio; estos trabajan ante una sociedad que concibe esta actividad poco deseable, lo cual es un motivo para que los jóvenes lustra calzados utilicen pasamontañas, siendo una estrategia para enfrentar los prejuicios sociales latentes.

\section{CARACTERÍSTICAS DEL COMERCIO AMBULANTE}

A continuación se describen las características de la actividad comercial ambulante, fruto de una investigación realizada entre los años 2004 y 2006 en la ciudad de El Alto (Luna, 2007) donde se entrevistó a un centenar de jóvenes comerciantes ambulantes. El trabajo de campo se realizó en las calles del sector de la Ceja y de la zona 16 de Julio los días jueves, sábados y domingos. Son jornadas de concurrencia de comerciantes y de clientes, por los bajos costos de una variedad de productos. En las entrevistas realizadas se pudieron identificar varios temas: género, migración campo-ciudad, actividades laborales en el campo, empleos en el área urbana, edad, experiencia de trabajo, situación familiar y el costo de inversión de la actividad comercial ambulante. Al final del desarrollo de la investigación se identifican los siguientes resultados: la actividad comercial ambulante es una estrategia de empleo para estudiantes de secundaria, que combinan el tiempo entre el estudio y la venta callejera. Además representa una actividad de refugio para ex trabajadores jubilados que dedican el resto de sus 
vidas a vender productos en pequeña cantidad. Mientras que en los comerciantes jóvenes, representa una actividad laboral en transición, sobre todo cuando no están en condiciones de acceder a un empleo fijo. Encuentran en la actividad ambulante un medio que les permite cubrir los gastos de sus estudios, es decir, programan su tiempo para la venta en la calle y después disponen del tiempo para ir al colegio.

En el contexto social de la ciudad de El Alto, ser joven significa una construcción social, cultural, política e identitaria de jóvenes de origen social aymara, quechua que viven en un imaginario urbano de contacto con valores y símbolos de la sociedad moderna. En ese orden, muchos comerciantes ambulantes de 15 a 24 años de edad provienen de las comunidades rurales aymaras y quechuas de los departamentos de La Paz, Oruro, Potosí y Cochabamba. En cambio, los otros sectores de comerciantes jóvenes son del área urbana de La Paz y El Alto. Esta diferencia de origen social se expresa en la interacción social entre comerciantes; por ejemplo, un joven comerciante que proviene del área rural del norte de Potosí, conversa más con su paisano que vende el mismo producto. Lo propio sucede con los jóvenes comerciantes urbanos, aunque sus padres provienen del campo, ellos están inmersos en el contexto urbano a través de los gustos por la música, el estudio, el deporte, las fiestas y las redes de amigos, lo que se expresa en el uso frecuente del castellano en reuniones de amigos, etc. Al respecto, Mario Yapu en una investigación sobre jóvenes aymaras de la ciudad de El Alto dice:

Los jóvenes inmigrantes la construyen sobre un conjunto de elementos sociales compartidos porque frecuentan los mismos lugares, tienen contactos con grupos similares de jóvenes, además de que poseen un mismo conjunto de elementos lingüísticos, somáticos, vestimenta, gustos musicales, hexis corporal, creencias religiosas, lugar de procedencia y otros (Yapu, 2008: 27).

O tra característica de la actividad ambulante es la cuestión de género, que se expresa por la presencia heterogénea de comerciantes jóvenes varones y mujeres. Por ejemplo, algunas jóvenes venden ropa interior femenina, otras venden anillos de fantasía y pulseras. En el caso, de jóvenes migrantes del área rural, se dedican a la venta de frutas de piñas y papaya. También las comerciantes se diferencian según la vestimenta que portan. Las que provienen del área rural portan pollera corta y sombrero. Son oriundas de la región norte del departamento de Potosí y sur del departamento de 0 ruro y en términos populares se denominan «cholitas». En cambio, las que venden frutas portan polleras largas al estilo de la mujer paceña. En ambas, los artículos que ofertan tienen poco que ver con los conocimientos acerca de gustos de moda, vestimenta y adornos predominantes de un contexto urbano; más bien, ofertan productos de la canasta familiar. En cambio las jóvenes que son de procedencia urbana en su mayoría venden ropas, adornos, pulseras, aretes, artículos para el maquillaje. Esto implica conocer los gustos o preferencia de los clientes en cuanto a moda, prototipo de belleza que se exige en el área urbana. O tras jóvenes ofertan productos similares a los varones, por ejemplo, champús, crema dental, productos de consumo masivo. 
Se identifican a ambulantes que venden condimentos como ají molido, anís, clavo de olor, condimento y canelas en carritos que recorren las calles de la zona de Villa Dolores de la Ceja. Estos comerciantes son de la región norte del departamento de Potosí y de la provincia Abaroa del departamento de O ruro. En las entrevistas realizadas a las comerciantes jóvenes, las que venden condimentos se diferencian étnicamente por el uso de la lengua y por la pollera corta que portan; mientras que los varones que venden el mismo rubro portan prendas acorde a una vestimenta urbana. Para vender los productos, tanto varones como mujeres ofertan en castellano, lo que permite tomar contacto con los clientes, más aún, en la ciudad de El Alto donde los clientes son bilingües aymara-castellano. El uso del castellano apertura contacto con clientes de habla aymara, y en otros con clientes que son castellanohablantes.

El capital económico que manejan los comerciantes ambulantes de condimentos no excede 500 bolivianos. O fertan sus productos por unidad: por ejemplo, venden canelas, condimentos desde uno a dos bolivianos envasados en bolsitas de plástico. Según los entrevistados, en un día de feria se vende entre 120 a 150 bolivianos, el resto de los días las ventas son reducidas.

0 tro producto vendido por los comerciantes jóvenes entre los 15 y 30 años, son los limones que alcanzan una inversión de 80 a 90 bolivianos. Estos productos se venden en bolsas de plástico de 5 a 25 limones con un precio de 5 a 20 bolivianos por envase. Estos comerciantes son de la provincia Bolívar del departamento de Cochabamba y otros del norte de Potosís; hablan el quechua cuando conversan entre paisanos en una esquina de la plaza o de la calle. Estos encuentros cotidianos permiten convivir en confianza y compartir las experiencias sobre la actividad ambulante. Con frecuencia transitan con sus carritos por las calles, algunos ofertan con megáfonos cuando están frente a una aglomeración de transeúntes, sobre todo los días sábado y domingo donde hay concurrencia de compradores. En esta situación compiten con los comerciantes de puestos fijos que, en algunos casos, venden los mismos productos que un comerciante ambulante, lo que significa, ofertar a precios de remate, siendo motivo de conflictos entre comerciantes.

0 tro sector de comerciantes ambulantes que predomina en la ciudad de El Alto son los que venden mercachifles, es decir ofertan productos como afeitadoras, ganchos, pegamentos, cinturones, cierres, pitas, corta uñas, candados, hilos, agujas, tijeras, cremas, papel higiénico, clínex, etc. Se trata de un bazar andante en un carro móvil. Estos ambulantes están organizados en la asociación 30 de Enero y en su mayoría cuentan con una edad entre 14 y 60 años. En los comerciantes jóvenes se identifican trayectorias sociales heterogéneas.

Primero, se trata de jóvenes que provienen del área rural del departamento de La Paz así como de los departamentos de O ruro, Potosí y Cochabamba. Entre los factores que influyen en la migración del campo a la ciudad está la desintegración

5 La Provincia Bolívar y el Norte de Potosí son parte de un mismo piso ecológico y cultural, aunque pertenece la provincia Bolívar a Cochabamba y el Norte de Potosí a la Provincia Bustillos del departamento de Potosí. 
involuntaria de la familia nuclear campesina; por ejemplo, si el hermano mayor se va a trabajar a la ciudad, lo probable es que los hermanos menores sigan el mismo camino. Por otro lado inciden las condiciones de pobreza de las familias campesinas, que impulsan a los jóvenes a buscar otras fuentes de ingreso fuera de las comunidades rurales. Otro factor que interviene son las redes sociales que posee una persona con su entorno familiar, paisanaje o de amistad6, lo que asegura conseguir un empleo eventual o de insertarse en la misma actividad comercial. Si un integrante de la familia nuclear es comerciante ambulante, este le colabora a su pariente cercano, primo, hermano para que pueda tener la misma actividad. En muchos casos, esta experiencia es compleja por las dificultades de contar con una vivienda propia, o de habitar en la vivienda de algún familiar que significa someterse a las obligaciones del entorno familiar que le cobija. Por ejemplo, Juana comerciante ambulante comentaba en 2006 que provenía de una provincia del departamento de La Paz y comenzó a trabajar desde que era niña, ya que sus padres fallecieron. Entonces, tuvo que comenzar ayudando a sus tíos a vender cafés por las mañanas en las calles de la Ceja de El Alto, después cuando ya era más joven se casó y conformó su familia, a partir de ahí, se aleja de la dependencia que tenía con sus parientes y se dedica como vendedora ambulante junto a su esposo.

En otros términos, para aquellos comerciantes que han pasado por una infancia y juventud en situación de trabajo, el comercio les ha permitido liberarse de ocupaciones laborales dependientes. En ese contexto, la formación escolar pasa a un segundo plano, encuentran en el comercio ambulante como una actividad de fácil acceso y de disposición de tiempo, que les permite generar sus propios ingresos económicos. Posteriormente cuando alcanzan alguna estabilidad económica, algunos deciden retomar estudio de secundaria o superior.

En cambio, otros jóvenes migrantes del área rural al arribar al área urbana, acceden a empleos eventuales con bajos sueldos, de acuerdo a las tareas manuales que no requieren de una cualificación técnica, aunque las funciones que realizan implican esfuerzo físico y responsabilidad. Es el caso de Carlos quien, en los años 2004 y 2005, trabajaba de comerciante ambulante. Por entonces tenía 20 años de edad, emigró al área urbana a sus 16 años e ingresó a trabajar en una tornería con un sueldo por debajo de 500 bs. El ambiente laboral donde trabajaba era riesgoso, porque un compañero de trabajo había sufrido un accidente en su mano, motivo por el cual decide abandonar su empleo y por influencia de su hermano que era comerciante ambulante, Carlos se dedica al comercio ambulante vendiendo alimentos, como zumos de papaya, plátano y naranja en un carrito a motor por el sector de la Ceja de El Alto.

6 Para los jóvenes que provienen del área rural, no hay diferencia entre contactos por amistad y paisanaje, representa un sinónimo. Si se trata de jóvenes que provienen de una misma provincia o pueblo rural, se colaboran como amigos. 


\section{EL SACRIFICIO DE LOS JÓ VENES POR UN EMPLEO : LA RELACIÓ N ENTRE EL COMERCIO Y LOS ESTUDIOS}

En el presente acápite se describe algunos casos de jóvenes comerciantes que en su vida transitaron por empleos precarios y la misma actividad comercial. La actividad laboral para algunos jóvenes comienza desde los 12 o 13 años, sin gozar de una remuneración monetaria, solo reciben como retribución de su trabajo vestimenta, útiles escolares y alimentación. Esto sucede con jóvenes que nunca tuvieron la protección de sus padres, porque los mismos han fallecido, o en otros casos, los papás se quedan en el campo, mientras los hijos se vienen a vivir a la ciudad traídos por algún familiar como un tío o una tía. El entorno familiar es el espacio donde comienzan a trabajar sin gozar de un sueldo, porque el mismo entorno considera el trabajo de un pariente que es menor de edad como una ayuda. Este tipo de labor se caracteriza también por la excesiva carga laboral, lo que valoran en el tiempo cuando son jóvenes, lo que significa ganarse un sueldo a través del ahorro e inversión en la actividad comercial.

Por ejemplo, Ramiro es un comerciante que proviene de Patacamaya, provincia Aroma del departamento de La Paz. Estudió en su pueblo natal hasta segundo de medio, luego emigró a la ciudad de El Alto a prestar su servicio militar en el regimiento Ingavi; después de salir del cuartel, adquiere un coche móvil para vender zumos de frutas. A diferencia de otros comerciantes, Ramiro recibió la colaboración de su padre con la inversión para el negocio, después se afilió a la asociación de ambulantes 20 de Julio que se aboca a vender jugos de naranja. Al respecto Ramiro decía lo siguiente:

Vengo de Patacamaya, mis papás me han ayudado con este negocio ellos han comprado el carro, el motor, no he trabajado en ninguna otra parte, en mi pueblo estaba hasta segundo medio, después me he venido al cuartel, ahora he vuelto a estudiar estoy estudiando en el Centro de bachillerato para Adultos, en Villa Adela, este ya va ser de mi propio.

Ramiro cuando ingresa al comercio ambulante, está influenciado por sus paisanos que vendían en la asociación de ambulantes 30 de Enero; pero el apoyo más importante lo recibe de su padre que le colaboran con la compra de un carro móvil y de los insumos para operar en el negocio. Ramiro comentaba que con el negocio se siente libre. Además, le permite estudiar en el programa de bachillerato para adulto en la zona de Villa Adela, es decir, le permite combinar el comercio con el estudio.

Efraín es otro comerciante ambulante con 25 años de edad que proviene de Tiahuanaco. Sus padres fallecieron cuando apenas tenía ocho años. A raíz de esa situación, sus tíos se hacieron cargo de él, emigró a la ciudad de El Alto a sus 12 años de edad, luego pasó por varios empleos. Primero trabajó de lustrabotas, luego en una costurería y paralelamente trabajaba como ayudante de albañil. Efraín decía lo siguiente:

Quien me pagaba era persona desconocida, mi sueldo era de 80 bs. Hace tres años era 80 bs., semanal como ayudante de albañil, después pasé 
como ayudante de costura trabajaba semanalmente con su sueldo de 70 bs, semanal, mesa y puesto, ahí me daban comida, pero a pesar de que como ayudante de albañil no me daban.

Por tanto, los primeros empleos en el área urbana para aquellos jóvenes que provienen del área rural se caracterizan por ser eventuales, de baja remuneración, o el poco valor que le otorga el entorno social, familiar al trabajo de un menor de edad. En otros, el joven o la joven que viene del campo a la ciudad se caracteriza por mantenerse en una constante búsqueda de empleo o actividad laboral por cuenta propia. Por esta razón algunos comienzan a trabajar como ayudantes de albañil, costura, cocina, lustra botas, o ayudan a un familiar a vender en un negocio, trabajos que no requieren de una formación técnica, documento o certificados que acrediten el conocimiento del oficio. El grado de capital cultural que posee un joven del área rural, no necesariamente debe estar acreditado por un título o certificado; más bien, es importante tener experiencia, aquello que Bourdieu llama capital incorporado (Bourdieu, 1998). Asimismo, la habilidad en ejercer un oficio, la experiencia y el esfuerzo definen el tiempo de permanencia en un empleo, y el mismo vínculo familiar, social son medios para encontrar un empleo o para ingresar al comercio ambulante.

En otro caso, Ruth es una joven de 20 años de edad. Ella, al igual que otras jóvenes, sale a vender cada sábado y domingo por la avenida Tiahuanaco de la Ceja de El Alto. Vende lápices labiales, aretes, pulseras, adornos, collares, objetos relacionados con la belleza facial de las mujeres. Comenta que desde hace dos años, la mercadería que posee es de su propiedad con una inversión que no sobrepasa los mil bolivianos que fue ahorrando de a poco. La mercancía que comercializa es delicada por las características del producto. Esto afecta la seguridad de tener ganancias, además las comerciantes de puestos fijos, siempre la molestan quitándole la mercadería; luego es difícil obtener la devolución de las prendas por el costo elevado, entonces prefiere perder.

Ruth tiene seis hermanos; todas sus hermanas estudian, entre ellas dos hermanas mayores están en la escuela Normal de Maestros Simón Bolívar de La Paz, una de sus hermanas menores estudia en la Universidad y sus dos menores hermanos están bajo el cuidado de sus padres. Su padre es albañil, su madre ama de casa. Primero comenzó a vender ayudando a sus hermanas que lo hacían por la avenida Tiahuanaco; dice que intentó trabajar en un restaurante pero no le fue bien porque le pagaban muy poco. Estando en el colegio tuvo a su bebé, por tal motivo tienen el negocio para sostener los gastos que su bebé requiere y además le permite cubrir el gasto de sus estudios. Ruth con el negocio que cuenta se considera una persona independiente, porque mantiene a su bebé con su venta, aunque también el papá del niño le colabora con los gastos. Con su negocio, Ruth evita pedir dinero a sus padres. Además, la experiencia que ha tenido desde muy joven hace que no tenga dificultad para vender sola, y esté afiliada a la asociación 30 de Enero la más antigua de El Alto.

O tro caso es el de Fernando, de 16 años de edad, que está cursando el segundo grado de secundaria en el Colegio Juan Capriles de la Ceja de El Alto. Es de 
la misma ciudad de El Alto, mientras que sus padres son migrantes del campo. Fernando se dedica a vender cepillos, pasta dental en un carro móvil, también los fines de semana, sábado y domingo. El negocio donde vende pertenece a sus padres, los fines de semana les ayuda a vender porque sus papás le apoyan economícamente para que pueda estudiar en el colegio. Para Fernando la venta es una colaboración voluntaria a la actividad de sus padres porque nadie le está obligando a vender.

El resto de los días de lunes a viernes se dedica a sus estudios, asiste a clases por las mañanas y por las tardes hace sus tareas; en algunas ocasiones le ayuda a vender a sus papás. Aproximadamente hace un año que está vendiendo como ambulante. Según Fernando, existen otros compañeros de curso que también ayudan a sus padres, no precisamente en el negocio, sino en otras actividades laborales, como en talleres 0 en un negocio de puesto fijo. Similar situación ocurre con sus compañeras de colegio, con quienes se encuentra en la calle, que también ayudan a vender a sus mamás en los puestos fijos. Por el momento Fernando piensa continuar estudiando, salir bachiller e ingresar a la universidad para estudiar Economía; dice que le gusta la matemática.

Roxana es una comerciante ambulante de 31 años de edad, tiene dos hijos, un varón de 14 y otro de 10 años de edad; desde muy joven comenzó a vender como ambulante. Roxana apenas pudo cursar hasta tercero de primaria; por falta de recursos económicos no pudo continuar con sus estudios de primaria. Además sus padres se habían separado y no tenía apoyo económico para solventar sus gastos, motivo por el cual se fue a vivir donde su abuelo quien desde su infancia la mantiene económicamente. Por ello, desde muy joven se ve obligada a trabajar, a esto se suma, la responsabilidad de mantener a sus hijos ya que su concubino ha fallecido. El negocio representa un patrimonio propio que fue ahorrando en forma sacrificada. Vende todos los días en la avenida Tiahuanaco, actividad que le permite sostener a sus hijos que están estudiando.

Finalmente, se evidencia el incremento de la actividad comercial ambulante por la diversidad de productos que ofertan los comerciantes ambulantes en carros móviles. Por una parte, esta actividad genera competencia entre ellos por ofertar los mismos productos a precios similares. Esto configura un escenario social dinámico, donde las trayectorias sociales se caracterizan en el caso de los jóvenes comerciantes, en la capacidad de combinar el tiempo, entre la actividad comercial y el estudio. En el caso de los jóvenes que provienen del área rural, se advierte una trayectoria de vida que se expresa en el sacrificio, esfuerzo, lo que en parte determina el futuro de estos jóvenes que deciden volverse comerciantes y conforman su familia como un hito que rompe toda forma de relación de dependencia con el entorno familiar. En cambio en otros, la inserción al comercio ambulante está mediada por la influencia de algún miembro del entorno familiar, tanto de los que provienen del área rural, como también de aquellos que se consideran citadinos o urbanos, mientras que sus padres son migrantes del área rural. 


\section{CONCLUSIÓN}

El comercio ambulante en la ciudad de El Alto representa una fuente de trabajo e ingresos económicos para miles de jóvenes varones y mujeres, que se dedican a vender una variedad de productos en carritos móviles. Se trata de una actividad que exige poca inversión de capital, siendo los jóvenes un sector importante que se aboca a dicha actividad en calles, plazas, esquinas, boca calles, de los sectores de la Ceja y la feria 16 de Julio de la ciudad de El Alto de La Paz. Muchos jóvenes a parte de realizar comercio estudian en colegios, universidades 0 en un instituto. Por ello, es importante contar con una actividad económica que no exige horario ni subordinación, sino es libre, independiente y autónomo, y les permite aspirar como personas a un mejor estatus social y condiciones de acceso a un empleo formal o que asegure ingresos económicos estables. En este caso, el comercio ambulante es una actividad transitoria para los jóvenes, porque tienen objetivos de mejorar las condiciones laborales a través de su formación en centros de formación superior.

Sin embargo, se advierten diferencias entre los jóvenes que provienen del área rural con los del área urbana. En ambos casos comparten una misma identidad al tener procedencia aymara o quechua. Pero los que provienen del área rural desde temprana edad asumen responsabilidades con la familia nuclear o con el entorno familiar, se vuelven jefes o jefas de hogar, se hacen de esposos o esposas. Este hecho determina que la persona se dedique exclusivamente al trabajo; en este caso, el comercio ambulante representa una actividad económica que ocupa a cientos de familias jóvenes que provienen del área rural. M ientras que los jóvenes del área urbana si bien se dedican al comercio ambulante, paralelamente se dedican al estudio o siempre se encuentran estudiando en algun centro educativo. A partir de esa condición adquieren una independencia económica respecto a sus progenitores.

\section{Referencias citadas}

ARDAYA, G., 1988 - Trabajadoras informales en La Paz: el caso de las vendedoras ambulantes. In: El sector informal urbano en Bolivia (EDO BOL): 189-221; La Paz: Facultad Latinoamericana de Ciencias Sociales (FLACSO ), Centro para el Desarrollo Labora y Agrario (CEDLA).

ARTEAGA, V. \& LARRAZABAL, N., 1988 - La mujer en la crisis económica, las vendedoras ambulantes de La Paz, 140 pp., La Paz: Centro de Promoción de la M ujer Gregoria Apaza.

BO URDIEU, P., 1998 - La Distinción, criterios y bases sociales del gusto, 520 pp.; Madrid: Taurus.

CACHÓN, L., 2001 - ¿Movilidad social o trayectoria de clase?, 480 pp.; Madrid: Siglo Veintiuno Editores. 
CAN AVIRE-BACARREZA, G. \& MARISCAL, M ., 2010 - Políticas macroeconómicas, choques externos y protección social en Bolivia, 110 pp.; La Paz: Unidad de Análisis de Políticas Económicas y Sociales (UDAPE).

ESCÓBAR, S. \& GUAYGUA, G., 2008 - Estrategias familiares de trabajo y reducción de la pobreza en Bolivia, 220 pp.; Buenos Aires: Consejo Latinoamericano de Ciencias Sociales (CLACSO).

FERNÁNDEZ, E. J., 2001 - Estrategias de movilidad social en el municipio de El Alto, 108 pp.; La Paz: Centro de Promoción de la Mujer Gregoria Apaza.

GÁlVEZ, N. \& JARAMILLO, E., 2002 - Niños trabajadores del Perú, 101 pp.; Lima: Universidad Nacional Mayor de San Marcos (UNMSM)-Fondo Editorial de la Facultad de Ciencias Sociales.

INSTITUTO NACIONAL DE ESTADÍSTICA (INE), 2014 - Censo Nacional de Población y Vivienda 2012, en http://www.ine.gob.bo

LUNA ACEVEDO , H., 2007 - Trayectorias sociales, laborales, de comerciantes ambulantes de las asociaciones 30 de enero, y 20 de julio de la ciudad de El Alto, 166 pp.; La Paz: U niversidad Mayor de San Andrés (UM SA). Tesis de Licenciatura.

PEREIRA, M. R., BRIDIKHINA, E. \& MONTAÑO, J. G., 2009 - Para escuchar las voces de la calle: el comercio en vía pública en La Paz, 140 pp.; La Paz: Programa de Investigación Estratégica en Bolivia (PIEB).

PREALC, 1988 - Sobrevivir en la calle: comercio ambulante en Santiago, 182 pp.; Santiago: O rganización Internacional del Trabajo (O IT).

QUISPE, D., TO NCONI, F. \& CAN AVIRI, C., 2011 - Warmis Alteñas en el puesto de la vida: testimonio económico y político de las mujeres del comercio minorista en la ciudad de El Alto, 329 pp.; El Alto: Centro Promoción de la Mujer Gregoria Apaza.

ROJAS, C. B., 1992 - La batalla por las calles, 78 pp.; La Paz: Centro de Desarrollo Laboral y Agrario (CED LA), texto inedito.

SANDOVAL, Z. G. \& SOSTRES, M. F., 1989 - La ciudad prometida: pobladores y organizaciones sociales en El Alto, 230 pp.; La Paz: Instituto Latinoamericano de Investigaciones Sociales (LDIS).

SCARNECCHIA, A. \& CAVAGN OUD, R., 2013 - Los chicos lustra calzados de La Paz: el uso del pasamontañas como forma de máscara y símbolo de identidad. Bulletin de I'Institut Français d'Études Andines, 42 (3): 491-503.

SOTO, H. D., 1986 - El otro sendero: la revolución informal, 230 pp.; Bogotá: O veja Negra.

TASSI, N., M EDEIROS, C., RODRÍGUEZ-CARMO NA, A. \& FERRU FINO, G., 2013 - Hacer plata sin plata: El desborde de los comerciantes populares en Bolivia, 286 pp.; La Paz: Programa de Investigación Estratégica en Bolivia (PIEB).

YAPU, M., 2008 - Jóvenes Aymaras, sus movimientos, demandas y políticas públicas, 117 pp.; La Paz: Universidad del Programa de Investigación Estratégica en Bolivia (U-PIEB). 